\title{
POLÍTICAS SOCIALES ORIENTADAS A LAS JUVENTUDES: REVISIONES CRÍTICAS SOBRE LAS NOCIONES DE CAPITAL HUMANO Y EMPLEABILIDAD EN LAS INTERVENCIONES ESTATALES EN ARGENTINA
}

youth-oriented social policies: critical reviews on the notions of human capital and employability in state interventions in argentina

\section{Rebeca Cena'}

"No es necesario [que el pueblo] perciba la verdad de la usurpación: introducida en otro tiempo sin razón, se ha vuelto razonable; conviene mostrarla como auténtica, eterna y ocultar su comienzo si no se quiere que llegue rápidamente a su fin" (PASCAL, citado en FORRESTER, 1999, p. 2)

\section{Resumen:}

El objetivo de este artículo es problematizar los modos en que las políticas sociales direccionadas a las juventudes construyen las problemáticas que dicen abordar. El cruce entre políticas sociales y juventudes, permite advertir una serie de intervenciones estatales que -siendo resultado de procesos de disputas- manifiestan una determinada imagen del mundo. En este escrito retomamos una de las dimensiones constitutivas del concepto de imagen del mundo: la construcción de problemas. En este sentido se analizan una serie de intervenciones estatales que implementadas durante los años 2015 y 2019 en las ciudades de Villa María y San Francisco (Argentina) involucran dentro de su población destinataria a las juventudes. Se concluye que los modos de intervención estatal orientados a las juventudes se encuentran constituidos por las nociones de empleabilidad y capital humano, siendo expresión de uno de los modos en que capitalismo, Estado y neoliberalismo se asientan con la lógica de la competencia y "empresa de sí".

Palabras clave: Juventudes, Políticas Sociales, Capital Humano, Empleabilidad.

\section{Abstract:}

The objective of this article is to problematize the ways in which social policies aimed at young people build the problems they claim to address. The cross between social policies and youth, allows us to notice a series of state interventions that - being the result of dispute processes - manifest a certain image of the world. In this paper we return to one of the constitutive dimensions of the concept of the image of the world: the construction of problems. In this sense, a series of state interventions that are implemented during the years 2015 and 2019 in the cities of Villa María and San Francisco (Argentina) involving youths are analyzed. It is concluded that the modes of state intervention aimed at youths are

\footnotetext{
1 Doctora en Ciencias Sociales (UBA), Magister en Derechos Humanos y Democratización en América Latina y el Caribe (UNSAM) y Licenciada en Sociologia (UNVM). Becaria Postdoctoral del Consejo Nacional de Investigaciones Científicas y Técnicas-Universidad Nacional de Villa María, docente de la Universidad Nacional de Río Cuarto, miembro del Centro de Investigaciones y Estudios Sociológicos, investigadora Junior del Grupo de Trabajo Internacional de CLACSO "Sensibilidades, subjetividades y pobreza", editora de la Revista Latinoamericana de Estudios sobre Cuerpos, Emociones y Sociedad. Correo electrónico: rebecena@gmail.com, ciudad: Villa Maria, Córdoba, Argentina
} 
Políticas sociales orientadas a las juventudes: revisiones críticas sobre las nociones de capital humano y empleabilidad en las intervenciones estatales en Argentina| Rebeca Cena

constituted by the notions of employability and human capital, being expression of one of the ways in which capitalism, State and neoliberalism settle down with the logic of competition and "selfenterprise".

Keywords: Youth, Social Policies, Human Capital, Employability.

\section{Introducción}

Las juventudes y las politicas sociales han concentrado un marco amplio de investigaciones y producciones científicas con una gran cantidad de desafios, comenzando por la definición sociológica del concepto de juventudes que se vuelve una tarea, al menos, compleja. No obstante, en el abordaje y definición de las juventudes, el Estado ${ }^{2}$-a partir de sus intervenciones sociales- se constituye en un referente ineludible. A partir de sus instituciones -familia, escuela, etc.-, políticas públicas y normativas, participa de los términos en que se construyen y clasifican los grupos sociales (BOURDIEU, 2000, LENOIR, 1979, VÁZQUEZ, 2015). En este marco analítico, el objetivo de este escrito es analizar las políticas sociales orientadas a las juventudes en función de uno de los componentes centrales del concepto de imagen del mundo: la construcción de problemas sociales. Esto significa, explorar los modos en que las juventudes han sido conceptualizadas, construidas y visualizadas desde las intervenciones sociales del Estado en relación a determinadas situaciones vueltas cuestión.

Las políticas sociales juegan un rol central en los procesos de producción, creación y reproducción de sociabilidades (DE SENA, 2016). Pues constituyen modos de intervención que suponen y configuran determinados modos de ser, estar y habitar las condiciones problemáticas que, al mismo tiempo, contribuyen a delimitar. Las politicas sociales, desde la perspectiva aquí presentada, se posicionan como elementos centrales de los regimenes de acumulación capitalista (OFFE, 1990) al constituir un vínculo nodal entre éste y las condiciones de vida de la población (BARBA

\footnotetext{
2Para una ampliación del concepto de Estado en relación a las políticas sociales trabajados en este escrito ver Oszlak y O'donnell (1981) y Grassi (2003).
} 
Políticas sociales orientadas a las juventudes: revisiones críticas sobre las nociones de capital humano y empleabilidad en las intervenciones estatales en Argentina| Rebeca Cena

SOLANO, 1995). Estos modos de intervención estatal implican así modos de hacer sociedad (DANANI, 2009, DE SENA, 2014) que desde una serie de esquemas de valores compartidos (DONATI y LUCAS, 1987) retoman y redefinen problemas vueltos cuestión, identifican y construyen sujetos $\mathrm{y}$ subjetividades, establecen cursos de acción posibles, así como también bienes y servicios desde los cuales abordar las situaciones problema. Es decir, poseen determinadas imágenes del mundo (SCRIBANO, DE SENA y CENA, 2015) que establecen sujetos, problemas y soluciones. La imagen del mundo, es aquí comprendida como un conjunto de presuposiciones, que hacen que algunos elementos del mundo social emerjan a la vista y otros se solapen (CENA, 2014), estableciendo lo aceptado, lo aceptable y los modos legitimos de alcanzar la reproducción. Estas politicas sociales, entonces, en tanto políticas de Estado condensan las posibilidades de nominar, significar y hacer (DE SENA, 2016).

En el caso particular de este escrito, se trabajan a las politicas sociales orientadas a las juventudes. El abordaje de las juventudes ha sido una tarea compleja para las Ciencias Sociales, pues la mayoría de las aproximaciones científicas ha caído en obstáculos derivados de un abordaje en tanto categoria administrativa (BELMONTE, 2016), con al menos, tres consecuencias: la politización sociológica que ha observado a las instituciones públicas y los modos en que éstas han demandado actuaciones y delimitaciones de lo que en cada momento se ha considerado joven; de las fuentes secundarias a partir de las cuales se ha relevado datos respecto a las juventudes que han focalizado en la edad como un criterio clasificatorio de las estadísticas, como los censos y encuestas que han construido sus muestras en función de la edad; y de la voluntad de comparar resultados entre investigaciones, lo que ha llevado a una uniformidad de criterios, conceptualizaciones y metodologías (BRUNET y PIZZI, 2013).

En este sentido, dentro de las conceptualizaciones de las juventudes, se encuentra un amplio campo de investigación, debate y conceptualización. Pues uno de los principales problemas que ha enfrentado la tarea de delimitarlas es poder alcanzar una serie de dimensiones teóricas que 
Políticas sociales orientadas a las juventudes: revisiones críticas sobre las nociones de capital humano y empleabilidad en las intervenciones estatales en Argentina| Rebeca Cena

habilitaran a problematizar la realidad social de las juventudes. En este sentido se han realizado una serie de concesiones al empirismo, no haciendo una ruptura epistemológica a partir de la construcción de un referente teórico que permitiera establecer a las juventudes en tanto categoría sociológica del objeto "los jóvenes" (LEMUS, 1998).

La tarea de su teorización ha llevado a una serie de obstáculos que han permutado el referente teórico de las juventudes, por su referente empírico. De esta manera se les ha otorgado un valor en sí mismo al establecer que el ser joven indica "poseer un gran porvenir", "posibilidad de cambio", "momento de transición", etc. No obstante, para Lemus (1998) el problema es poder establecer un concepto de juventudes que dé cuenta de su relacionalidad y relatividad, dado que se puede ser joven en determinado contexto para determinadas actividades y viejo para otras. En este sentido, las juventudes poseen diferentes formas de manifestarse y solo una de ellas es la duración. De allí que para el autor sea necesario agregar variables como clase social, género, región, etnia y momento histórico.

En esta misma línea Brunet y Pizzi (2013) sostienen que con juventudes se alude a situaciones diversas que solo tienen en común la edad y que solo ese criterio no justifica su tratamiento como un todo homogéneo (CRIADO, 1998). En este sentido, Brunet y Pizzi (2013) sostienen que este tipo de perspectivas abogan por una supuesta condición juvenil que comparten los sujetos de una determinada edad, pero no se demuestra que lo compartan ni que sea diferente en otras etapas de la vida. Pues las delimitaciones por edad deberían ser reflexionadas y decididas previamente por el investigador en relación a la muestra que ha decidido construir.

Con este abanico teórico en este escrito se propone, entonces, explorar una serie de políticas sociales que, orientadas a las juventudes, contribuyen a su delimitación. Para ello se particulariza en un componente de la imagen del mundo: la construcción de problemas. Las intervenciones del Estado poseen determinadas imágenes del mundo que dan cuenta de la construcción de la problemática que realizan al establecer sujetos 
Políticas sociales orientadas a las juventudes: revisiones críticas sobre las nociones de capital humano y empleabilidad en las intervenciones estatales en Argentina| Rebeca Cena

destinatarios, recursos, cursos de acción, diagnósticos, responsabilidades y responsabilizaciones.

Para tal propósito y luego de esta introducción que permite problematizar la temática, se plantea el siguiente camino argumentativo: en primer lugar se explicitan las decisiones metodológicas a partir de las cuales se ha orientado el trabajo de campo en relación al análisis documental y entrevistas; en segundo lugar, se discuten algunas nociones vinculadas a las teorias del capital humano y la noción de empleabilidad. Estas dimensiones han permeado el diseño y ejecución de las políticas sociales analizadas, dando cuenta de una particular estrategia de construcción de la problemática. Pues las politicas sociales, tal como se ha adelantado, participan de las disputas alrededor de la construcción y delimitación de problemas sociales estableciendo sujetos, adjetivaciones, objetivos, cursos de acción, recursos, etc. Por último, se ofrecen una serie de reflexiones finales que permiten continuar dialogando en las conexiones posibles y exploradas entre regímenes de acumulación, políticas sociales, neoliberalismo y juventudes.

\section{Metodología}

La estrategia metodológica que ha guiado la construcción de datos que aquí se presentan, deriva del proyecto de investigación aludido en la introducción. La construcción de datos estuvo centrada en dos etapas fundamentales. En primer lugar, se realizó un análisis documental (SOLANILLA, 2007) para facilitar la reconstrucción de los modos en que han sido abordadas las juventudes y sus problemáticas en el diseño de las diferentes políticas sociales (de corte nacional, provincial y/o municipal) implementadas en los territorios de Villa Maria y San Francisco. Dicho análisis permitió una sistematización de las intervenciones estatales hacia las y los jóvenes, a partir del tipo de política, sus objetivos, población destinataria, bienes y/o servicios que ofrece, entre otras dimensiones.

En segundo lugar, se desarrollaron entrevistas (DE SENA, 2012) a agentes estatales que estuvieran vinculados a la gestión, ejecución y/o 
Políticas sociales orientadas a las juventudes: revisiones críticas sobre las nociones de capital humano y empleabilidad en las intervenciones estatales en Argentina| Rebeca Cena

evaluación de las políticas sociales bajo estudio. Aquí el objetivo fue adentrarnos a los marcos de referencia de los entrevistados, y, por tanto, acceder a los modos en que la realidad (en este caso respecto de las políticas sociales en su vinculación con las juventudes) es interpretada, vivida, sentida y percibida. Es decir, se buscó la reconstrucción de los modos y significados en que las problemáticas de las juventudes fueron y son definidas y establecidas en el período de referencia.

Las entrevistas abarcaron las distintas áreas y dependencias que a nivel local desarrollan, gestionan y/o ejecutan acciones orientadas a las juventudes. Se trabajó con 9 entrevistas con una duración de entre 40 y 90 minutos cada una, las mismas fueron grabadas y transcriptas de manera textual resguardando la identidad de las personas entrevistadas. Los agentes estatales refieren a los "portavoces" de las politicas sociales orientadas a las juventudes estudiadas. Es decir, aquellos agentes que, en tanto, gestores, planificadores y ejecutores de las políticas sociales en cuestión nos acercan a los significados y características que asumen tales intervenciones estatales en los territorios de Villa María y San Francisco. Tales portavoces autorizados como informantes instituidos (COMBESSIE, 2005), ocupan una posición de responsabilidad y referencia en las diferentes secretarias, oficinas, agencias y/o dependencias municipales, provinciales y nacionales; y ofrecen puntos de vista vinculados a la ejecución concreta de las políticas sociales.

La interpretación de los datos aquí presentados se ha dado en relación a la noción de imagen del mundo. La misma se encuentra conformada por 4 componentes, de los cuales aquí se ha retomado: la construcción de problemas sociales. Para ello, se ha identificado dentro de las politicas sociales trabajadas cuáles han sido las problemáticas sociales identificadas, cuál ha sido el objetivo que se han planteado en tanto situación a modificar, cuáles las dimensiones constitutivas de las problemáticas construidas, cuáles los fundamentos de las intervenciones estatales, etc. 
Políticas sociales orientadas a las juventudes: revisiones críticas sobre las nociones de capital humano y empleabilidad en las intervenciones estatales en Argentina| Rebeca Cena

Tal como se ha explicitado en la introducción, la noción de imagen del mundo alude a una serie de supuestos a partir de los cuales las intervenciones sociales del Estado operan. Es decir, una serie de esquemas de clasificación y división del mundo a partir de los cuales determinados elementos emergen a la vista y otros se solapan. En la tabla I, pueden observarse las dimensiones analiticas mencionadas.

Tabla I: Dimensiones de análisis del concepto de Imagen del Mundo

\begin{tabular}{|l|l|}
\hline Componente de imagen del mundo & Aspecto a observar en la política social \\
\hline Construcción de problemas & -Objetivo; \\
& -Fundamentación de la intervención; \\
& -Situación a resolver; \\
& -Situación presentada como cuestión; \\
& -Aspectos que movilizan la intervención estatal \\
\hline
\end{tabular}

Fuente: elaboración propia en base a Scribano, De Sena y Cena (2015)

Hacia un abordaje de los problemas sociales vinculantes a las juventudes: ¿Qué significa el Capital Humano en las políticas sociales?

En el marco de las creencias que se producen y reproducen en las sociedades, aquella que asocia movilidad social ascendente y educación se ha impuesto y continúa reproduciéndose con fuerza. En este sentido, la educación pese a mostrar su insuficiencia para la movilidad social ascendente y ocupacional, sigue alimentando expectativas sociales (ARONSON, 2007). Dicha creencia se encuentra en los horizontes de vida de las poblaciones (DE SENA, 2017), ha guiado el diseño e implementación de políticas públicas por parte de los Estados (CENA, 2014), al tiempo que ha acompañado las recomendaciones, financiamientos y estudios realizados por los organismos internacionales (OCDE/CEPAL/CAF, 2016). De hecho, los extendidos Programas de Transferencias Condicionadas de Ingresos en la región latinoamericana, han basado su diseño y ejecución en este supuesto básico: la educación constituye un medio para la movilidad social 
Políticas sociales orientadas a las juventudes: revisiones críticas sobre las nociones de capital humano y empleabilidad en las intervenciones estatales en Argentina| Rebeca Cena

ascendente (OCDE/CEPAL/CAF, 2016). No obstante, luego de más de 20 años de implementación de este tipo de políticas sociales que han tomado como base la influencia sobre la educación en los sectores en condiciones de pobreza, se ha concluido que los resultados no han sido los esperados: "si bien estos programas han "revolucionado la asistencia social (palabras del informe) en todo el mundo" los beneficiarios de estos programas siguen siendo pobres, con baja escolaridad e inestabilidad laboral, claro que posiblemente la situación de estas personas sería aún peor sin dichos programas" (STAMPINI y TORNAROLLI, 2012 citado en DE SENA, 2018: 25). Lo que se ha denominado teorias del capital humano aluden a una serie significativa de trabajos, teorizaciones e investigaciones que, con diferentes grados de complejidad, han intentado analizar las vinculaciones entre educación, producción y trabajo (ARONSON, 2007). Si bien ha sido Schultz (1961) quien ha acuñado el término Capital Humano argumentando que la inversión en educación generaria altas tasas de retorno, pueden rastrearse algunos antecedentes en Slow (1957) y Deninson (1962) que comenzaron a indagar las relaciones posibles entre educación y trabajo (ACEVEDO, MONTES, MAYA, et. al. 2007).

En la década de los 50 y 50 del siglo XX comienza hablarse explícitamente de capital humano y del ser humano como un elemento central de la producción empresarial y crecimiento económico (ARONSON, 2007). En las definiciones clásicas del concepto se alude a "los conocimientos en calificación y capacitación, la experiencia, las condiciones de salud, entre otros, que dan capacidades y habilidades, para hacer económicamente productiva y competente a las personas, dentro de una determinada industria" (ACEVEDO, MONTES, MAYA, et. al. 2007, p. 5). Entonces, hablar de capital humano no implica reducir la mirada a la educación, sino también refiere a la acumulación de conocimientos generales y específicos (BECKER, 1964) y la experiencia (MINCER, 1974). Desde esta perspectiva, los componentes centrales del capital humano aludirían a la educación formal, experiencia adquirida en los puestos de 
Políticas sociales orientadas a las juventudes: revisiones críticas sobre las nociones de capital humano y empleabilidad en las intervenciones estatales en Argentina| Rebeca Cena

trabajo, entrenamientos laborales y salud (ACEVEDO, MONTES, MAYA, et. al. 2007).

El capital humano ha afectado el diseño y ejecución de políticas sociales por parte de los Estados, principalmente aquellas orientadas a las juventudes. Pues tal como hemos expuesto en la introducción de este escrito, las problemáticas a partir de las cuales las juventudes se han posicionado como agentes de la intervención estatal se han relacionado a los entrenamientos laborales, la educación, la capacitación y la formación para el trabajo (OCDE/CEPAL/CAF, 2016; CENA y GONZÁLEZ, 2019).

En la siguiente tabla se ha sistematizado algunos de los componentes constitutivos de las políticas sociales orientadas a las juventudes analizadas. Teniendo como referencia el concepto de imagen del mundo previamente aludido, se ha particularizado en los modos en que se construyen las problemáticas sobre las que intervenir. En este primer apartado se ha trabajado con aquello que las políticas sociales analizadas han sostenido en sus diseños y normativas. Para tal propósito se ha construido la siguiente tabla con: las políticas sociales orientadas a las juventudes, el objetivo textual que las mismas se proponen y los elementos que se desprenden de esos objetivos vinculados a las teorías del capital humano.

Tabla II: Construcción de problemas en las políticas sociales orientadas a las juventudes. Componente: objetivos

\begin{tabular}{|c|c|c|}
\hline Política & Objetivo & Elementos \\
\hline $\begin{array}{l}\text { Programa Jóvenes } \\
\text { con Más y Mejor } \\
\text { Trabajo (nacional) }\end{array}$ & $\begin{array}{c}\text { "Generar oportunidades de inclusión social y laboral para los } \\
\text { jóvenes, a través de acciones integradas, que les permitan } \\
\text { construir el perfil profesional en el cual deseen desempeñarse, } \\
\text { finalizar su escolaridad obligatoria, realizar experiencias de } \\
\text { formación y prácticas en ambientes de trabajo, iniciar una } \\
\text { actividad productiva de manera independiente o insertarse en } \\
\text { un empleo" (OIT) }\end{array}$ & $\begin{array}{c}\text { Formación obligatoria; } \\
\text { Experiencia y prácticas } \\
\text { de trabajo; }\end{array}$ \\
\hline $\begin{array}{l}\text { Programa Primer } \\
\text { Paso (provincial) }\end{array}$ & $\begin{array}{l}\text { "Tiene por objeto facilitar la transición hacia el empleo formal } \\
\text { de jóvenes desempleados, mediante la realización de procesos } \\
\text { de capacitación y entrenamiento en ambientes de trabajo de } \\
\text { empresas o empleadores privados con la finalidad de } \\
\text { desarrollar actitudes, conocimientos y habilidades, similares a }\end{array}$ & $\begin{array}{l}\text { Capacitación y } \\
\text { entrenamientos; } \\
\text { Actitudes, } \\
\text { conocimientos y } \\
\text { habilidades; }\end{array}$ \\
\hline
\end{tabular}

3 Fuente: https://www.oitcinterfor.org/experiencia/programa-jóvenes-más-mejor-trabajo-mteyssargentina 
Políticas sociales orientadas a las juventudes: revisiones críticas sobre las nociones de capital humano y empleabilidad en las intervenciones estatales en Argentina| Rebeca Cena

\begin{tabular}{|c|c|c|}
\hline & $\begin{array}{c}\text { las que se requieren para desempeñarse en ámbitos } \\
\qquad \text { laborales" } 4\end{array}$ & \\
\hline $\begin{array}{lr}\text { Programa } & \text { de } \\
\text { Respaldo } & \text { a } \\
\text { Estudiantes } & \text { de } \\
\text { Argentina } & \\
\text { (Progresar) } & \end{array}$ & $\begin{array}{l}\text { "Acompañar a los jóvenes para que terminen sus estudios } \\
\text { primarios y secundarios, y continúen en la educación superior o } \\
\text { se formen profesionalmente para ayudarlos en su desarrollo } \\
\text { personal, incluyendo laboralmente a todos aquellos que hasta } \\
\text { hoy no podían hacerlo" } 5\end{array}$ & $\begin{array}{l}\text { Formación obligatoria; } \\
\text { Formación profesional; }\end{array}$ \\
\hline $\begin{array}{l}\text { Programa de } \\
\text { Experiencia Laboral } \\
\text { de Jornada Corta } \\
\text { para Mujeres Por } \\
\text { Mi }\end{array}$ & $\begin{array}{l}\text { "El programa Por Mí busca que mujeres cordobesas, jefas de } \\
\text { hogar desempleadas que tengan } 25 \text { años cumplidos y hasta } \\
\text { llegar a la edad de jubilación o percepción de la Pensión } \\
\text { Universal para Adultos Mayores; o bien mujeres de } 18 \text { a } 25 \\
\text { años con hijos a cargo, puedan acceder a prácticas laborales } \\
\text { que les permitan capacitarse y lograr experiencia para } \\
\text { enfrentar al mercado laboral formal en el futuro"6 }\end{array}$ & $\begin{array}{l}\text { Prácticas laborales; } \\
\text { Capacitación; } \\
\text { Experiencia; }\end{array}$ \\
\hline
\end{tabular}

Tal como puede observarse en la tabla II, dentro del componente “objetivo" de las políticas sociales orientadas a las juventudes, se encuentran los elementos constitutivos de las perspectivas del capital humano aludidas. Elementos como la formación, experiencia y prácticas laborales, capacitación y entrenamientos, actitudes, conocimientos y habilidades, experiencia, son incorporados en los objetivos de las politicas sociales orientadas a las juventudes. Estos elementos son posicionados como parte de la construcción de la problemática que las politicas sociales contribuyen a delimitar, a partir de la concreción de acciones, medidas y recursos. Las políticas sociales participan, de este modo, de las disputas por la definición y abordaje de las problemáticas vueltas cuestión. En el caso de las intervenciones estatales orientadas a las juventudes aquí analizadas, incorporando como parte de las situaciones identificadas como problemas, medidas vinculadas a elementos de lo conocido como capital humano.

En la introducción a este escrito, se ha advertido que cuando se analizan las intervenciones del Estado en términos de imagen del mundo, lo

\footnotetext{
4 Fuente: https://empleo.cba.gov.ar/ppp-ppp-aprendiz/

5 Fuente: https://www.argentina.gob.ar/educacion/becasprogresar/institucional

6 Fuente: https://empleo.cba.gov.ar/taller-de-empoderamiento-y-busqueda-de-empleo-para-laspostulantes-del-por-mi/
} 
Políticas sociales orientadas a las juventudes: revisiones críticas sobre las nociones de capital humano y empleabilidad en las intervenciones estatales en Argentina| Rebeca Cena

que se está haciendo es explicitar aquellos esquemas de clasificación y división a partir de los cuales las políticas sociales son diseñadas, ejecutadas y evaluadas. Pues toda política social es el resultado de un proceso de interpretación, disputa y negociación (CENA, 2019) que se concretiza en un modo particular de abordar las problemáticas expresión de la cuestión social. Ahora bien, tal como se ha desarrollado en este apartado, las teorias del capital humano han permeado el desarrollo de las políticas sociales estableciendo como ejes prioritarios de la intervención aspectos vinculados a la formación, educación y experiencia laboral.

Dentro de las críticas y observaciones que se han realizado a las teorías del capital humano, se encuentran aquellas que en los años sesenta identificaron dos debilidades a estas producciones teóricas: la educación no producía los efectos en el desarrollo económico que se esperaba y existía una débil conexión entre formación y remuneraciones (ARONSON, 2007). Complementariamente con ello, se comprobó que los principios meritocráticos solo funcionaban dentro de las instituciones educativas que los pregonaban, al tiempo que Thurow (1983) argumentó que los contrastes salariales eran producto de la estructura del mercado de trabajo y no de las capacidades individuales de los asalariados e identificó la existencia de desempleados o subempleados con títulos. La segmentación salarial parecía estar más vinculada a sexo, clase y raza que a factores educativos (ARONSON, 2007).

Complementariamente con estas observaciones, se encuentra aquella vinculada a la linealidad. Pues para Becker el capital humano era un stock inmaterial imputable a una persona, aludiendo a una linealidad temporal que le servía para sentirse protagonista de su propia vida, una trayectoria lineal y acumulativa. No obstante, ni las trayectorias son lineales, ni las regularidades empíricas variables explicativas (ARONSON, 2007), ni existen relaciones causales entre los elementos previamente aludidos. Pues desde las perspectivas críticas, los aspectos a tener en cuenta para el mercado de trabajo no son solamente las cualificaciones técnicas, sino que se requieren de otros elementos como la raza, el sexo, la edad, el origen étnico y las 
Políticas sociales orientadas a las juventudes: revisiones críticas sobre las nociones de capital humano y empleabilidad en las intervenciones estatales en Argentina| Rebeca Cena

credenciales formales (BOWLES y GINTIS, 2014).

Raymond Boudon (1987) problematizó los desarrollos de las teorias del capital humano haciendo un aporte significativo: el carácter dual de la educación. Si ésta era problematizada como bien de consumo era algo a lo que los individuos tenían derecho, por lo que debería ser un objetivo esencial de las politicas sociales y acciones de los Estados. No obstante, como bien de inversión nada garantiza que la distribución igualitaria de la educación disminuya las desigualdades sociales (ARONSON, 2007).

Las politicas sociales permeadas por las teorias del capital humano, entonces, adolecen de un diagnóstico complejo de la realidad social, cediendo ante la trampa de dos situaciones que previamente se han advertido: la individualización de las problemáticas y la autoresponsabilización (CENA, 2014). Pues "en definitiva atribuye los males sociales o personales a los fallos de los individuos o a las necesidades técnicas inevitables de la producción. Proporciona, en suma, una buena ideología para la defensa del statu quo" (BOWLES y GINTIS, 2014: 228). En este sentido, las politicas sociales permeadas por las teorias del capital humano, construyen las problemáticas que movilizan la intervención estatal a partir de elementos relacionados con atributos, aspectos y características depositadas en su individualidad. En el apartado siguiente se tensionará estos elementos con la noción de empleabilidad, aspecto que emerge desde las narraciones de los agentes del Estado.

\section{Hacia un abordaje del concepto de "Empleabilidad"}

"En todos los paises avanzados, empresarios, altos funcionarios internacionales, intelectuales mediáticos y periodistas de alto vuelo se han puesto de acuerdo en hablar una extraña neolengua cuyo vocabulario -aparentemente surgido de la nada-está en todas las bocas: "mundialización" y "flexibilidad"; "gobernabilidad" y "empleabilidad"; "underclass" y "exclusión"; "nueva economía" y "tolerancia cero"; "comunitarismo", "multiculturalismo" y sus primos "posmodernos": etnicidad, minoría, identidad, fragmentación, etc. De esta nueva vulgata planetaria están notoriamente ausentes términos como capitalismo, clase, explotación, dominación y desigualdad, perentoriamente anulados bajo pretexto de obsolescencia o de presunta impertinencia" (BOURDIEU y WACQUANT, 2000, p. 12)

Las juventudes han emergido como una categoría de problematización desde las politicas sociales bajo análisis. Tal como se ha mencionado 
Políticas sociales orientadas a las juventudes: revisiones críticas sobre las nociones de capital humano y empleabilidad en las intervenciones estatales en Argentina| Rebeca Cena

previamente dentro de las intervenciones estatales a nivel nacional, provincial y/o municipal las juventudes han sido una preocupación. Tal es así que en las dos ciudades bajo análisis se concentran 18 intervenciones con diversos niveles jurisdiccionales. Las discusiones sobre las juventudes aluden necesariamente a un concepto relacional (GONZÁLEZ y BRUNIS, 2018) incorporando diversas dimensiones constitutivas. Dentro de los condicionamientos para el abordaje del concepto (como la generación, clase, raza y territorio), las politicas sociales ocupan un lugar significativo en tanto intervenciones estatales que concentran recursos, definiciones de la población junto con sus adjetivaciones, delimitación de las problemáticas que las afectan, así como también de los modos de abordajes.

En esta sección del escrito, se recuperan a los agentes estatales, que refieren a los "portavoces" de las políticas sociales orientadas a las juventudes estudiadas. Es decir, aquellos agentes que, en tanto, gestores, planificadores y ejecutores de las intervenciones sociales en cuestión permiten acceder a los significados y características que éstas asumen. Tales portavoces autorizados como informantes instituidos (COMBESSIE, 2005), ocupan una posición de responsabilidad y referencia en las diferentes secretarías, oficinas, agencias y/o dependencias municipales, provinciales y nacionales; y ofrecen puntos de vista vinculados a la ejecución concreta de las políticas sociales direccionadas a las juventudes (CENA y GONZÁLEZ, 2019).

A partir de las narraciones de los agentes estatales se ha elaborado la tabla III que se presenta a continuación. La misma cuenta con la identificación jurisdiccional de la política social con la que se ha trabajado, fragmentos de la narración de los técnicos y técnicas estatales involucrados en la gestión de la política social vinculados a los objetivos de las intervenciones estatales y las dimensiones y elementos analiticos que se desprenden de dichas expresiones.

Tabla III: Construcción de problemas en las narraciones de agente estatales vinculados a políticas sociales orientadas a las juventudes. Componente: objetivos

\begin{tabular}{|l|l|l}
\hline Jurisdicción & Objetivo & Elementos \\
\hline
\end{tabular}


Políticas sociales orientadas a las juventudes: revisiones críticas sobre las nociones de capital humano y empleabilidad en las intervenciones estatales en Argentina| Rebeca Cena

\begin{tabular}{|c|c|c|}
\hline Nacional & $\begin{array}{l}\text { "... el principal es el Programa Jóvenes que apunta a personas } \\
\text { de } 18 \text { a } 24 \text { años, que no hayan terminado el secundario o } \\
\text { primario, y dentro del Programa Jóvenes lo que tiene son varias } \\
\text { prestaciones que la idea principal es que ayudan a mejorar su } \\
\text { empleabilidad" (N18/1). }\end{array}$ & Empleabilidad \\
\hline Local & $\begin{array}{l}\text { "la gestión tiene una intención de poder profundizar estas } \\
\text { herramientas de discusión democrática en los jóvenes, por } \\
\text { ejemplo el Mercosur Joven, o todos los talleres que hay en } \\
\text { educación que tienen que ver con la accesibilidad al secundario } \\
\text { o a brindarle herramientas a los jóvenes para que puedan } \\
\text { terminar sus estudios, y también acompañado de programas } \\
\text { provinciales que acompañan a que el joven se inserte } \\
\text { laboralmente, nosotros tenemos el área de empleo que desde } \\
\text { ahí se coordinan se vinculan, por eso nosotros trabajamos muy } \\
\text { mancomunadamente se vinculan todos los jóvenes con su } \\
\text { primer experiencia laboral que eso acompaña a la idea que } \\
\text { tenemos en la secretaria de incluirlos dentro del sistema de } \\
\text { trabajo formal a la mayor cantidad de jóvenes posible" " (L18/2) }\end{array}$ & $\begin{array}{l}\text { Terminar estudios } \\
\text { Brindar herramientas } \\
\text { Inserción laboral } \\
\text { Inclusión dentro del trabajo } \\
\text { formal }\end{array}$ \\
\hline Nacional & $\begin{array}{l}\text { "son un conjunto de prestaciones que llevan a que la persona } \\
\text { no sólo se prepare para la empleabilidad, sino que sienta la } \\
\text { necesidad de terminar el colegio" (L18/1) }\end{array}$ & $\begin{array}{l}\text { Empleabilidad } \\
\text { Terminar colegio }\end{array}$ \\
\hline Nacional & $\begin{array}{l}\text { "Digamos un joven que esté dentro del programa, ponele que } \\
\text { entró a los } 18 \text { y va a estar hasta los } 24 \text {, por ejemplo, ese es el } \\
\text { caso, el objetivo es que quede en blanco antes o que tenga su } \\
\text { emprendimiento" (N18/11) }\end{array}$ & $\begin{array}{l}\text { Trabajo en blanco } \\
\text { Emprendimiento }\end{array}$ \\
\hline Provincial & $\begin{array}{l}\text { "enseña oficios, oficios para la gente que necesita buscar, } \\
\text { conseguir trabajo o para reconvertirse laboralmente" (P18/1) }\end{array}$ & $\begin{array}{l}\text { Oficio } \\
\text { Conseguir trabajo } \\
\text { Reconversión laboral }\end{array}$ \\
\hline Provincial & $\begin{array}{l}\text { "son muchas cosas que se ponen en juego y la personalidad del } \\
\text { alumno, las actitudes que tiene que tener hoy en día para } \\
\text { buscar o conseguir trabajo son muchas o más quizás del } \\
\text { conocimiento que tengas (...)" (P18/10) }\end{array}$ & $\begin{array}{l}\text { Actitudes para buscar } \\
\text { trabajo } \\
\text { Conocimiento para el } \\
\text { trabajo }\end{array}$ \\
\hline
\end{tabular}

El concepto de empleabilidad ha sido extensamente abordado $\mathrm{y}$ estudiado por los profesionales del trabajo (Rentería-Pérez y Malvezzi, 2008). Formichella y London (2013), historizan el concepto de empleabilidad y lo vinculan al vocablo inglés "employability", que se constituyó en un neologismo producto de palabras como empleo "employ" y habilidad "hability". Las primeras expresiones han utilizado el término en la década del 50 del siglo $\mathrm{XX}$, referenciando a aquellas personas con dificultades para insertarse en el mercado de trabajo. Hacia finales de los 60 resurge el 
Políticas sociales orientadas a las juventudes: revisiones críticas sobre las nociones de capital humano y empleabilidad en las intervenciones estatales en Argentina| Rebeca Cena

concepto en Europa, producto de la preocupación institucional para abordar el desempleo.

El concepto de empleabilidad hacia inicios del siglo XX en Estados Unidos y Gran Bretaña, aludía a una categoría dicotómica: se era o no empleable en función de tres criterios nodales: la edad, las condiciones de salud y las cargas familiares ${ }^{7}$ (RENTERÍA-PEREZ y MALVEZZI, 2008). En los 70 el concepto se amplía permeando las medidas e intervenciones de los Estados que se encuentran vigentes hasta la actualidad

\begin{abstract}
"fue considerada una medición de deficiencias de calificación profesional, movilidad y presentación, revelando la distancia entre características individuales y requerimientos de producción y aceptabilidad en el mercado de trabajo, lo cual se tradujo en programas de intervención orientados al entrenamiento para la selección y en otros programas complementarios sobre "cómo vestir" o "cómo presentarse" a una entrevista de trabajo" (RENTERÍA-PEREZ y MALVEZZI, 2008, p. 321).
\end{abstract}

La empleabilidad se ha constituido en un concepto versátil que reducidamente se ha vinculado a las habilidades para el trabajo y ha signado un número significativo de situaciones. Pues tal como sostiene Rentería-Pérez y Malvezzi (2008) la empleabilidad ha comenzado como una categoría teórica para expresar la relación entre la competitividad en el mercado de trabajo y las condiciones presentadas por los individuos. No obstante, su desarrollo ha hecho que se termine configurando como una categoría práctica para dar cuenta de la dinámica de inclusión-exclusión de los individuos en el mercado de trabajo. En este sentido, en tanto categoría ha tenido un fuerte impacto en el diseño y ejecución de medidas estatales orientadas a abordar las problemáticas del desempleo

"el constructo empleabilidad enriqueció el campo de las estrategias más que el de los conocimientos técnicos sobre el individuo. Es aquí donde radica la importancia de identificar entre otras cosas (ENRÍQUEZy RENTERÍA, 2007), los procesos de socialización que conllevan a la construcción de estrategias de desarrollo, la elaboración de las evaluaciones para la producción y aprehensión de la empleabilidad" (RENTERÍA-PEREZ y MALVEZZI, 2008, p. 320).

Dicho concepto no solamente ha permeado los diagnósticos vinculados a las problemáticas del mercado de trabajo, sino que también ha acompañado los procesos de creación de políticas sociales y su

\footnotetext{
7 Se vuelve relevante aquí dar cuenta de la clasificación como "inempleables" de las mujeres en condiciones de pobreza, sin terminalidad educativa y con hijos a cargo a partir de una medida estatal en 2004 en Argentina. Ver al respecto Weisburd (2011).
} 
Políticas sociales orientadas a las juventudes: revisiones críticas sobre las nociones de capital humano y empleabilidad en las intervenciones estatales en Argentina| Rebeca Cena

implementación. Pues dentro de la imagen del mundo contenida en las políticas sociales analizadas, la empleabilidad, la formación para el trabajo y la reconversión para el trabajo han sido características sobresalientes. Las perspectivas críticas han identificado que el concepto de empleabilidad se encuentra orientado hacia la responsabilidad individual (RENTERÍA-PEREZ y MALVEZZI, 2008). Pues desde los años 80 del siglo pasado ha sido un concepto con mucha variabilidad que si bien se ha utilizado fuertemente por entidades gubernamentales para guiar la implementación de políticas y programas no ha asumido un contenido concreto (FINN, 2003). La empleabilidad ha aludido a las características individuales de adaptabilidad al trabajo (FUGATE y ASHFORTH, 2003), a poder tener un empleo, mantenerlo y poder movilizarse a otros (BROWN y HESKETH, 2004, HARVEY, 2001), obtención y preparación para un trabajo (LEES, 2002), a la vez que cualidades técnicas y administración de incertidumbres e inseguridades (BRUTTIN, 2003).

"Carrieri y Sarsur (2002) observan otro aspecto al asumir la empleabilidad como un recurso y estrategia adaptada por la alta administración para transferir la responsabilidad de contratación y despido de la organización al trabajador, aislándolo de cambios ambientales, desligándola de su papel fundamental en las instituciones Empresa y Estado. En este sentido, más que una capacidad o cualidad individual, la noción de empleabilidad se convierte en un recurso para la explicación de cuestiones relacionadas con la inclusión y exclusión del mercado de trabajo, como la propuesta por Hirata (1997)" (RENTERÍA-PEREZ y MALVEZZI, 2008, p. 323-324)

En este sentido, la noción de empleabilidad no es más que una dimensión que refuerza y acompaña las teorías del capital humano en los procesos de intervención estatal analizados. En el apartado siguiente se profundiza sobre un tópico significativo que emerge de los procesos de construcción de problemas sociales en relación al capital humano y la empleabilidad: la noción de culpabilización.

\section{La moratoria que no fue: la culpabilización}

En la introducción al presente escrito, se ha dado cuenta de algunas interpretaciones en relación a las juventudes desde la sociología de la 
Políticas sociales orientadas a las juventudes: revisiones críticas sobre las nociones de capital humano y empleabilidad en las intervenciones estatales en Argentina| Rebeca Cena

juventud. En dichas interpretaciones, las instituciones han jugado un rol central en establecer qué es y que no es ser joven (CRIADO, 1998). En el caso de lo aquí analizado, las políticas sociales orientadas a las juventudes han afectado las condiciones en que las juventudes han emergido como un agente relevante para el Estado, estableciendo adjetivaciones, criterios de diferenciación, atribuido comportamientos, capacidades y problemáticas.

En el marco del régimen de acumulación capitalista las juventudes han asumido determinadas características (BRUNET y PIZZI, 2013) que las diferencian de otros roles, atributos y adjetivaciones, incluso su propia "existencia" o "visibilidad" como grupo social diferenciado y diferenciable. Pues no siempre las juventudes han sido una categoría de diferenciación de otros grupos sociales. Complementariamente con ello, ejes como el género, la raza y la clase constituyen elementos diferenciadores de las juventudes (LEMUS, 1998), por lo que en el contexto de este escrito se vuelve al menos necesario problematizar.

La categoría de moratoria social atribuida a las juventudes, históricamente ha sido asociada a la desresponsabilización y el ocio privilegiado en relación al futuro (ALVARADO, POSADA y GAVIRIA, 2009). No obstante, dicho atributo requiere ser tensionado dado que en su surgimiento fue asociado a las condiciones de vida de los sectores sociales medios y altos en relación a la planificación, uso del tiempo y responsabilidades. La moratoria social en el caso de las juventudes receptoras de las políticas sociales bajo análisis, no adviene como tal. Pues una de las preocupaciones explícitas de las políticas sociales analizadas es la preparación, formación y capacitación para el mercado de trabajo.

De este modo, los problemas atribuidos las juventudes expresados en las políticas sociales analizadas, hacen que éstas en tanto grupo social diferenciado sean configuradas desde la falta: para el mercado de trabajo y de tiempo disponible. Pues incluso antes de ser jurídicamente contratables en el mercado de trabajo, una preocupación de las intervenciones del Estado es su empleabilidad. En este sentido, la empleabilidad y el capital humano se constituyen en categorias prácticas de clasificación y diferenciación de la 
Políticas sociales orientadas a las juventudes: revisiones críticas sobre las nociones de capital humano y empleabilidad en las intervenciones estatales en Argentina| Rebeca Cena

población, que producen y reproducen determinados criterios de aquello considerado empleable o desempleable, en este caso de las juventudes en condiciones de pobreza.

Históricamente las juventudes han sido objeto de categorizaciones y clasificaciones que han dificultado su aprehensión científica (CRIADO, 1998). De este modo, se ha confundido la conceptualización teórica o la construcción conceptual de qué son las juventudes, con lo que deberian ser. Así se les ha atribuido las moratorias vitales argumentando un gran porvenir o como factores de cambio (tal como lo expresan las perspectivas generacionalistas según Criado, 1998), o como sujetos en "preparación para", no complejizando su relatividad y relacionalidad, advirtiendo las diferentes formas de manifestarse siendo solo una de ellas la duración. En este punto variables como clase social, género, región y momento histórico son centrales (LEMUS, 1998) y en el caso de las politicas sociales bajo análisis más aún.

El concepto de culpabilización permite advertir algunas de las argucias que contiene la imagen del mundo analizada (CENA, 2014). Particularmente en relación al mercado de trabajo, GUARESCHI (1999) sostiene que la culpabilización es uno de los mecanismos más sutiles que opera en relación a las problemáticas del mercado de trabajo. Pues en la imagen del mundo de la política social analizada, existe una concepción específica de las juventudes y de las prácticas y valores presupuestos, que a modos de esquemas de clasificación "organizan" las intervenciones del Estado.

"Concluye que esta representación trae, entre muchos otros, la
atribución del exito y el fracaso exclusivamente a personas
particulares, olvidando completamente las causalidades históricas y
sociales. Hay una individualización de lo social y una deificación de
lo individual [...] De conceptos como estos se derivan las prácticas
actuales de culpabilidad psicológica, bien identificadas y analizadas
por Forrester, cuando muestra cómo el desempleo planificado y
sistemático de hoy que conduce a la exclusión de millones de
personas es legitimado por las teorías psicosociales. Las personas
son responsables individualmente de una situación económica
adversa e injusta. Para tales teorias lo social no existe."
(GUARESCHI, 1999, p. 150, traducción propia).

Estos abordajes de las problemáticas sociales asociadas a las juventudes, no permiten entonces comprender el carácter social, estructural 
Políticas sociales orientadas a las juventudes: revisiones críticas sobre las nociones de capital humano y empleabilidad en las intervenciones estatales en Argentina| Rebeca Cena

y del régimen de acumulación que poseen. Pues si observamos la situación de millones de juventudes latinoamericanas en condiciones de pobreza, veremos que $64 \%$ de las y los jóvenes -más de 100 millones- en la región latinoamericana vive en hogares pobres o clase media en condición de pobreza, con deficiente acceso a servicios públicos. Las tasas de desempleo son casi tres veces mayores entre las y los jóvenes, que entre las personas consideradas adultas, golpeando particularmente a las mujeres jóvenes (OCDE/CEPAL/CAF, 2016). Luego del abordaje crítico de las políticas sociales realizado, se observa que estos índices e indicadores no tienen tanto que ver con las condiciones de empleabilidad o capital humano de millones de jóvenes, sino con una característica que han asumido los regímenes de acumulación, donde las y los jóvenes son relegados a las peores posiciones.

Para finalizar este apartado es necesario poder reflexionar respecto a la imagen del mundo identificada en las políticas sociales y el neoliberalismo. En términos de Laval y Dardot (2013) la argucia del neoliberalismo es que se ha hecho razón, atravesando las prácticas sociales, impregnando y permeando con la lógica del mercado todas las esferas en que la vida se produce y reproduce. La competencia, el ser "empresario de sî" y el "disfrute" de esa vida signada por la competencia, los "desafios" y la "superación", dan cuenta de que el neoliberalismo del siglo XXI se ha instalado en lo más íntimo, en el caso de lo aquí analizado, en la imagen del mundo de las políticas sociales. Desde la perspectiva propuesta por los autores, entonces, el neoliberalismo del siglo XXI no es solamente una doctrina económica e ideológica, sino que se constituye en un proyecto de sociedad que comienza y termina con la "fabricación" de los seres humanos. Esto significa, con la afectación de lo que significa ser, estar, sentir y habitar -en este caso- contextos de pobreza intervenidos por políticas sociales orientadas a las juventudes.

\section{Reflexiones}

El objetivo de este escrito ha sido explorar los modos en que las políticas sociales orientadas a las juventudes, construyen las problemáticas 
Políticas sociales orientadas a las juventudes: revisiones críticas sobre las nociones de capital humano y empleabilidad en las intervenciones estatales en Argentina| Rebeca Cena

que dicen abordar. A partir del análisis documental de las normativas relacionadas a las intervenciones estatales y la realización de entrevistas a agentes estatales involucrados en su gestión y/o ejecución en los diferentes niveles gubernamentales, se ha argumentado que éstas se encuentran atravesadas por las teorias del capital humano y las nociones de la empleabilidad. Se ha observado también, que estos modos de intervención estatal sobre la vida de las juventudes forman parte de una racionalidad neoliberal que impregna todas las esferas de la vida social con la lógica de la competencia y del mercado.

En esta dirección y siguiendo la propuesta de Robert (2017), el nuevo espíritu del capitalismo actúa a través de una serie de factores ideológicos que se incorporan en las instituciones -como las politicas sociales- y se hacen cuerpo en los individuos. "Vivimos hoy, argumentan Boltanski y Chiapello, para el caso francés, el tercer espíritu del capitalismo. El primer espíritu estuvo vinculado a la ética protestante, estudiado por Weber; el segundo, al modelo burocrático y fordista, dominante en buena parte del siglo XX y, el actual, a la "ciudad por proyectos". Algunos de los pilares de ese nuevo espíritu del capitalismo son jefes no autoritarios; innovación y creatividad; cambio permanente; movilidad; empleabilidad y motivación" (ROBERTT, 2017, p. 183). Si se observan detenidamente los elementos constitutivos de las politicas sociales analizadas y su relación íntima con las teorias del capital humano y las nociones de empleabilidad, se advierte el carácter actitudinal que las mismas presuponen por parte de las juventudes sobre las que pretenden intervenir: entrenarse, capacitarse, ganar experiencia, formarse, etc.

Si ya se contaba con evidencia acerca de que las nociones de empleabilidad y capital humano habian influenciado las instituciones vinculadas directamente al mercado de trabajo, se ha observado aquí que las políticas sociales no son una excepción. Pues las mismas afectan no solamente la producción de mano de obra pasada y futura, sino que también influencian las condiciones de producción y reproducción de la vida de los 
Políticas sociales orientadas a las juventudes: revisiones críticas sobre las nociones de capital humano y empleabilidad en las intervenciones estatales en Argentina| Rebeca Cena

trabajadores actuales insertos o no en puestos de empleo. Estas corrientes, si con su influencia en el mercado de trabajo impactan en las aptitudes, disposiciones y actitudes para el empleo, en el caso de las políticas sociales afectan también los modos en que el mundo es interpretado, vivido y sentido por parte de las poblaciones excluidas y -como en el caso de las juventudesaún no incluidas dentro del mercado laboral a través de procesos de culpabilización e individualización de las problemáticas bajo el paraguas de la empleabilidad y el capital humano.

Finalmente, es necesario advertir que estos modos de intervención estatal sobre las condiciones de producción y reproducción de la vida de las juventudes se insertan en lo que Laval y Dardot (2013) han argumentado como la racionalidad neoliberal del siglo XXI. Pues el neoliberalismo, a través de la lógica mercantil y la lógica de la competencia, impregna la totalidad de las esferas de la vida, comenzando por los esquemas de precepción y clasificación del mundo. El "ser empresario de si", "hacer de la propia vida una empresa" y "superar los desafios" forman parte de los procesos de subjetivación de un neoliberalismo que más que doctrina económica e ideológica, se ha hecho cuerpo, racionalidad, prácticas y sentires, en vistas a un proyecto de sociedad que comienza y termina con la "fabricación de sujetos". 
Políticas sociales orientadas a las juventudes: revisiones críticas sobre las nociones de capital humano y empleabilidad en las intervenciones estatales en Argentina| Rebeca Cena

\section{Bibliografía}

ACEVEDO, M. C., MONTES, I., MAYA, J. J. V., GONZÁlEZ, M. N. V., \& MEJÍA, T. B. Capital humano: una mirada desde la educación y la experiencia laboral. Cuadernos de investigación, 56, 1-40, 2007.

ALVARADO, S. V., POSADA, J. E. M., \& GAVIRIA, D. A. M. Contextualización teórica al tema de las juventudes: una mirada desde las ciencias sociales a la juventud. Revista latinoamericana de Ciencias sociales, niñez y juventud, $7(1)$, 83-102, 2009.

ARONSON, P. P. El retorno de la teoría del capital humano. Fundamentos en humanidades, 8(16), 9-26, 2007.

BARBA-SOLANO, C. B. La politica social desde una perspectiva sociológica. Espiral,2(4), 27-41, 1995.

BELMONTE, J. A. T. Sociología de la juventud. Una revisión. Espacio Abierto, 25(3), 183-195, 2016

BOURDIEU, P. La "juventud" no es más que una palabra, en Sociologia y Cultura, México: Grijalbo, 2002.

Cuestiones de Sociologia. Madrid: Istmo, 2000.

BOURDIEU, P., \& WACQUANT, L. Una nueva vulgata planetaria. Le Monde Diplomatique, número 11, pp. 12-13, 2000.

BOWLES, S., \& GINTIS, H. El problema de la teoría del capital humano: una crítica marxista. Revista de economia critica, 18, 220-228, 2014.

BRUNET, I., \& PIZZI, A. La delimitación sociológica de la juventud. Última década, 21(38), 11-36, 2013.

CENA, R. Programas de transferencias condicionadas de ingresos y programas de empleo en Argentina: entre la responsabilización de los destinatarios y la individuación de la cuestión social. BoletínCientífico Sapiens ResearchN ${ }^{\circ}$ 4, Año 1, 2014

CENA, R. Discusiones en torno a los cuidados sociales:¿ hacia una triple jornada? Reflexiones desde poblaciones destinatarias de políticas sociales. Aposta, (81), 2019.

CENA, R. y GONZÁLEZ, M. "Juventudes y políticas sociales: ¿qué ven cuando te ven?" en " $1^{\circ}$ Congreso Latinoamericano de Ciencias Sociales de la 
Políticas sociales orientadas a las juventudes: revisiones críticas sobre las nociones de capital humano y empleabilidad en las intervenciones estatales en Argentina| Rebeca Cena

UNVM 2019 - Articulando diálogos políticos y académicos en Ciencias Sociales", organizado desde la Secretaria de Investigación y Extensión del I.A.P. de Ciencias Sociales de la UNVM. Villa María, junio de 2019.

COMBESSIE, J-C. El método en sociologia. Córdoba: Ferreyra Editor, 2005.

CRIADO, E. M. Producir la juventud: critica de la sociologia de la juventud. Ediciones AKAL, 1998.

DANANI, C. (2009). La gestión de la politica social: un intento de aportar a su problematización. En CHIARA, M. y DI VIRGILIO, M. Gestión de la politica social. Conceptos y herramientas, 25-51, Editorial UNGS, 2009.

DE SENA, A. Estudiantes de sociologia: ¿herederos como siempre?.Mosaico de sentidos: vida cotidiana, conflicto y estructura social, 153, 2013.

DE SENA, A. Las politicas hechas cuerpo y lo social devenido emoción.Estudios sociológicos editora, Buenos Aires, 2014.

DE SENA, A. Políticas Sociales, emociones y cuerpos. RBSE - Revista Brasileira de Sociologia da Emoção, v. 15, n. 44, p. 173-185, agosto de 2016.

DE SENA, A. La intervención social en el inicio del siglo XXI: transferencias condicionadas en el orden global. Estudios Sociológicos Editora, Buenos Aires, 2018.

Donati, P., \& Lucas, A. (1987). La política social en el Estado de Bienestar: el desafío de los sistemas complejos. Reis, (37), 57-68.

DE SENA, A., CENA, R. B., CHAHBENDERIAN, F., DETTANO, A., MONA, A. C., LAVA, M. D. P., \& SAENZ VALENZUELA, M. M. Las politicas sociales desde los Estudios Sociales de los Cuerpos y las Emociones: El mundo del No en la Educación y el Trabajo en Mujeres Jóvenes del Gran Buenos Aires, Centro de Investigaciones y Estudios Sociológicos, 2017.

DE SENA, A., DEL CAMPO, N., DETTANO, A., GARCÍA ACEVEDO, M., \& SAENZ VALENZUELA, M. La entrevista como modo de indagación social. Una experiencia compartida. En Clave Metodológica. Reflexiones de la Investigación Social. Buenos Aires: Cooperativas, 2012.

FORRESTER, V. E1 horror económico. Fondo de Cultura Económica, 1909.

GONZÁLEZ, M. y BRUNIS, L. Juventudes en construcción: la condición juvenil en sectores populares urbanos de ciudades de Córdoba -Argentina-. En Congreso Internacional de Investigadores sobre Juventud. Congreso llevado a cabo en el Palacio de las Convenciones, La Habana, 2018. 
Políticas sociales orientadas a las juventudes: revisiones críticas sobre las nociones de capital humano y empleabilidad en las intervenciones estatales en Argentina| Rebeca Cena

GRASSI, E. Politicas y problemas sociales en la sociedad neoliberal: la otra década infame (I). Buenos Aires: Espacio Editorial, 2003.

GUARESCHI, P. Pressupostos Psicosociais da Ex- clusão: Competitividade e Culpabilização. En SAWAIA, B. AsArtimañas da Exclusão. Analisepsicossocial e ética da desigualdade social, São Paulo: Editora Vozes, 2001.

LAVAL, C. y DARDOT, P. La nueva razón del mundo. Editorial Gedisa, 2013.

LEMUS, R. B. Hacia una sociología de la juventud. Algunos elementos para la deconstrucción de un nuevo paradigma de la juventud. Última década, (9), 1998.

RENTERÍA-PÉREZ, ERICO, \& MALVEZZI, SIGMAR . Empleabilidad, cambios y exigencias psicosociales en el trabajo. UniversitasPsychologica, 7(2), 2008.

OCDE/CEPAL/CAF, Perspectivas económicas de Amèrica Latina 2017: Juvenud, competencias y emprendimiento. OECD, Publishing, Paris, 2016.

OFFE, C., KEANE, J., \& ESCOHOTADO, A. Contradicciones en el Estado del Bienestar. Madrid: Alianza Editorial, 1990.

OSZLAK, O., \& O'DONNELL, G. Estado y políticas estatales en América Latina: hacia una estrategia de investigación. Redes, 2(4), 1995.

ROBERTT, P. El involucramiento del trabajador: una nueva doxa del capitalismo. En VERGARA, G, Y DE SENA, A.Geometrias Sociales, Estudios Sociológicos Editora, Buenos Aires, 2017.

SCRIBANO, A., DE SENA, A., \& CENA, R. B. Social policies and emotions in Latin America: A theoretical approach to their analysis. Corvinus Journal of $\begin{array}{llll}\text { Sociology and Social } & \text { Policy, }\end{array}$ http://dx.doi.org/10.14267/cjssp.2015.02.01

SOLANILLA, M. U. La metodología cualitativa para la investigación en Ciencias Sociales. Una aproximación "mediográfica". Intersticios. Revista sociológica de pensamiento crítico, 1(1), 2007.

VÁZQUEZ, M. Juventudes, políticas públicas y participación. Un estudio de las producciones socioestatales de la juventud en la Argentina reciente. Ciudad Autónoma de Buenos Aires: Grupo Editor Universitario, 2015.

WEISBURD, L. H., LABIAGUERRE, J. A., DE SENA, A., GONZÁlEZ, M., HOREN, B., MÜLlER, G., \& LABIAGUERRE, E. A. Problemas de género en la Argentina del siglo XXI: feminización de la pobreza e inequidad del 
Políticas sociales orientadas a las juventudes: revisiones críticas sobre las nociones de capital humano y empleabilidad en las intervenciones estatales en Argentina| Rebeca Cena

mercado laboral. CEPED-Universidad de Buenos Aires, Buenos Aires. Parte II: Propuestas de actividades, 2011. 